\title{
Erratum to: The probability of default in Russian banking
}

\author{
Alexander M. Karminsky ${ }^{1} \cdot$ Alexander Kostrov $^{1}$
}

Published online: 9 July 2015

(C) Eurasia Business and Economics Society 2015

\section{Erratum to: Eurasian Econ Rev (2014) 4(1):81-98 DOI 10.1007/s40822-014-0005-2}

On page 88, Fig. 3 'Withdrawals of licenses and bank defaults in the Russian banking sector: Q11998-Q32011', the legend has been published illegibly or incompletely. The author has provided a clearer illustration below (Fig. 3) to replace the published version.

This mistake happened during the production process of the article and unfortunately remained unnoticed.

The publisher apologises for this mistake.

The online version of the original article can be found under doi:10.1007/s40822-014-0005-2.

Alexander M. Karminsky

karminsky@mail.ru

Alexander Kostrov

kostrov.alexander.v@gmail.com

1 International Laboratory of Quantitative Finance, Higher School of Economics, Moscow, Russia 


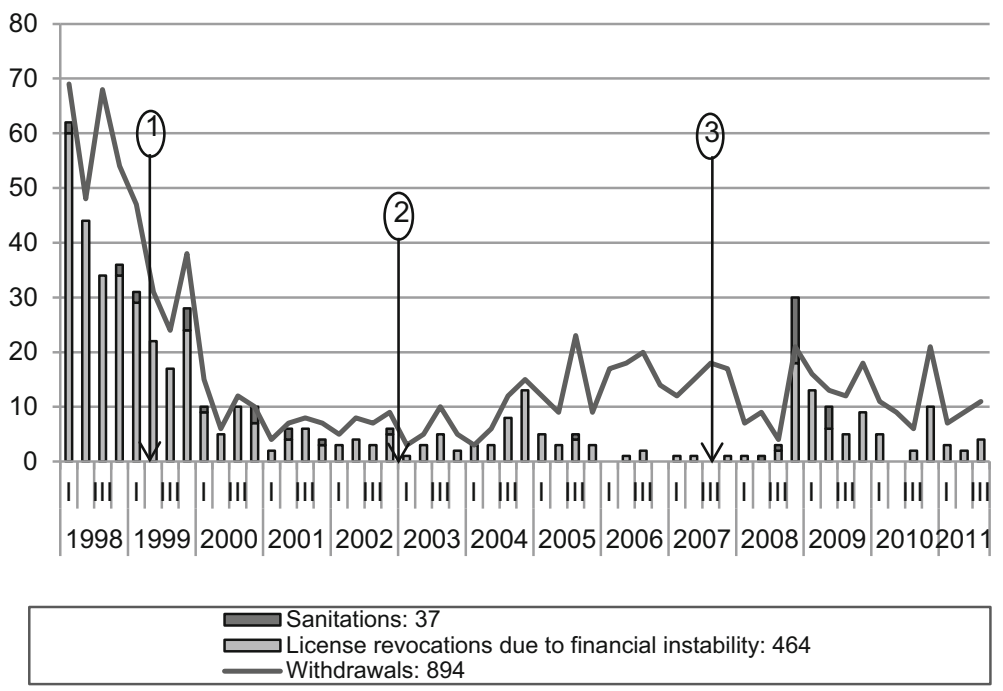

Fig. 3 Withdrawals of licenses and bank defaults in the Russian banking sector: Q11998-Q32011. Notes 1-(Jan. 2000) - effect of 1998-1999 crisis has almost expired; 2-(Jan. 2004)—the Deposit Insurance System was launched in Russia; 3-(Sep. 2008)-2008-2009 financial crisis started in Russia. Source Bank of Russia, authors' calculations 